include the deposition and distribution of documents, and diffusion of information. In particular, it is suggested that the organisation should provide at its central depot a universal primary bibliography, and should endeavour to secure the creation of a universal copyright system. It seems that with the establishment of the United Nations Educational, Scientific and Cultural Organisation, the proposals should, in the first instance, be considered by that body, presumably at the instance of one or other of the national delegations.

\section{Literature of Spectrochemical Analysis}

THE American Society for Testing Materials, through its Committee on Spectrographic Analysis, has sponsored the publication of two indexes on the literature of spectrochemical analysis. The first, issued in 1940, covered the years $1920-39$ and contained 1,467 references and a detailed subject index. The second, "Index to the Literature on Spectrochemical Analysis. Part II, 1940-1945", issued in January of this year, gives references to 1,044 publications on spectrochemical analysis that have appeared during the years $1940-45$ inclusive. In addition, there are thirty-six references, for the years 1938 and 1939, that were omitted from the earlier Index. The references are arranged in chronological order, and for each year the material is listed in alphabetical order according to the authors. English titles are given for all the papers, but foreign book titles are left untranslated. In the earlier Index abstracts were not given but only references to the published abstracts of the papers. Because of the widely scattered nature of the literature, and because many libraries probably lack complete sets of foreign periodicals for the war years, a brief abstract is provided, in Part II, for every spectrochemical publication listed. In most cases the abstracts are quoted verbatim from Chemical Abstracts, but where necessary, by consulting other abstracting journals and the original articles, a more suitable abstract has been compiled. This painstaking and intensive work, both of maintaining and compiling the Index, has been done under the direction of B. F. Scribner and W. F. Meggers, of the National Bureau of Standards, Washington. A helpful, detailed subject index, which covers the content rather than the titles of the several papers, completes the Index.

It is somewhat surprising that in spite of war-time restrictions on publication and the difficulties of access to foreign journals so much work has been done in the field of spectrochemical analysis during the War. The choice of spectrochemical methods in preference to others can only be attributed to the simplicity, speed, sensitivity and economy of these methods-all vital factors in war-time applications. With the return of industrial competition, these methods should prove equally valuable, and all spectrographers will find both Part II and the earlier Index indispensable as reference handbooks. The Index is clearly printed and bound in a paper cover, though for reference purposes in the laboratory it would have been preferable to have had a much heavier binding. Abbreviations are used extensively, and although no explanatory list is provided, no real difficulty will be experienced in understanding the text. The addition of a list of the full titles and addresses of periodicals to which reference is made would perhaps be an improvement. Copies of the Index can be obtained from A.S.T.M. Headquarters, 1916 Race Street, Philadelphia 3, Pasadena.

\section{Nature Lover: The Magazine of the Countryside}

THe recent publication of volume 4, No. 1 of Nature Lover, the magazine of the countryside, marks the revival of a much-needed popular journal which deals with the natural history and archæology of the British countryside. The greatest merit of the journal is that it chooses good, representative subject. matter which is fairly easily available, thus bringing these rural sciences within the reach of everyman. The present number contains short, readable articles on the "Unity of Nature" by C. H. Warren, "Secretive Badgers" by B. M. Nicholas, "British Fritillary Butterflies" by L. H. Newman, "Jimmy the Lizard" by Frances Pitt, "The Numbers of Animals" by Brian Vesey-Fitzgerald, "Water Problems of Fishes" by Chapman Pincher, "Some Strange Plant Habits" by Wolseley Banks, "Bird-watching on an East Coast Estuary" by R. H. Harrison, "Lavenham, Suffolk" by Geoffrey Morgan. Among these authors are some of Britain's best natural history writers, and some of the articles are illustrated by good photographs. This monthly journal can be strongly recommended to the general lay reader who is interested in country-life and natural history, and it should be encouraged in all our secondary schools, for its method of presentation is bound to stimulate interest. Subscription to Nature Lover is $16 s$. 6d. a year, including postage. Further information can be obtained from Nature Lover, Staples House, Cavendish Place, London, W.1.

\section{U.S. National Academy of Sciences : Officers}

According to the annual statement, the present officers and members of the Council of the U.S. National Academy of Sciences are as follow : President: Prof. Alfred N. Richards, professor of pharmacology, University of Pennsylvania ; Vice-President : Dean L. P. Eisenhart, Graduate School of Mathematics, Princeton University; Foreign Secretary : Prof. Detlev W. Bronk, Johnson professor of biophysies, University of Pennsylvania ; Home Secretary : Dr. F. E. Wright, Geophysical Laboratory, Carnegie Institution, Washington; Treasurer: Dr. J. C. Hunsaker, Departments of Mechanical Engineering and Aeronautical Engineering, Massachusetts Institute of Technology. Other Members of Council: Dr. Walter R. Miles, Prof. W. Albert Noyes, jun., Prof. I. I. Rabi, Dr. W. M. Stanley, Dean John T. Tate and Dr. D. D. Van Slyke.

\section{Rook Behaviour during Incubation}

CLOSELY studying a rookery of eight nests during the incubation period, C. M. Ogilvie noticed that the hen birds applied themselves almost exclusively to incubation, while excursions were rare and very brief. (British Birds, 40, No. 5 ; May, 1947.) Feeding and coition, when this occurred, took place upon the nest. The cock bird was responsible for feeding the hen, a duty which was performed with characteristic ceremony at irregular intervals; intrusions within the colony and invasions from without were combated by the male birds. Coition was more often promiscuous than between mated pairs, and took the form of an assault resisted by the hen and countered by other cocks.

\section{University of Leeds: Appointments}

THE following appointments in the University of Leeds have been announced: Mr. E. A. Vaughan, lecturer in the Department of Social Studies; Mr. 